\title{
Symptomatic cholelithiasis may be the first sign of sarcoidosis
}

\author{
Durat Akalın' \\ Semra Demirli Atıcl \\ Dudu Solakoğlu Kahraman² \\ iD Cem Tuğmen ${ }^{1}$
}

1. University of Health Sciences Tepecik Training and Research Hospital, Department of General Surgery, Izmir, Turkey 2. University of Health Sciences Tepecik Training and Research Hospital, Department of Pathology, Izmir, Turkey

\section{SUMMARY}

Sarcoidosis is a multisystemic noncaseating granulomatous disease that rarely affects the gastrointestinal system. The initial diagnosis of sarcoidosis with gallbladder/gallbladder-associated lymph node involvement is a very rare condition in the literature. Herein, we aimed to report a case of newly diagnosed sarcoidosis with lymph node involvement associated with the gallbladder.

KEYWORDS: Sarcoidosis. Cholelithiasis. Gallbladder.

\section{INTRODUCTION}

Sarcoidosis is a chronic, multisystemic inflammatory disorder of unknown etiology. The disease is more commonly seen in females than males and may affect all organs at various rates ${ }^{1,2}$. Although the disease mostly affects the pulmonary and lymphoid systems, it rarely affects the gastrointestinal system. Sarcoidosis of the gallbladder and lymph node associated with the gallbladder is an extremely rare clinical entity.

Herein, we aimed to report a case of newly diagnosed sarcoidosis with a postoperative examination of the cholecystectomy specimen.

\section{Case Presentation}

A 69-year-old female patient presented to our clinic with symptoms of nausea, vomiting, and right upper quadrant pain. She had type 2 diabetes mellitus and a history of operation for left breast carcinoma and endometrial carcinoma. She did not receive chemotherapy or radiotherapy in the postoperative follow-up period. The patient was admitted to the emergency department twice due to biliary colic symptoms. Gastroscopy was performed because of the history of oncological operation. Gastroscopy was unremarkable and showed no pathology. Abdominal ultrasonography showed multiple stones of 3-4 mm in the gallbladder lumen. Laboratory tests were unremarkable with normal range liver function tests and normal white blood cell levels. The patient was scheduled for elective surgery due to symptomatic cholelithiasis. Preoperative chest X-Ray was normal without parenchymal lesions or hilar/mediastinal lymphadenopathy. Laparoscopic 

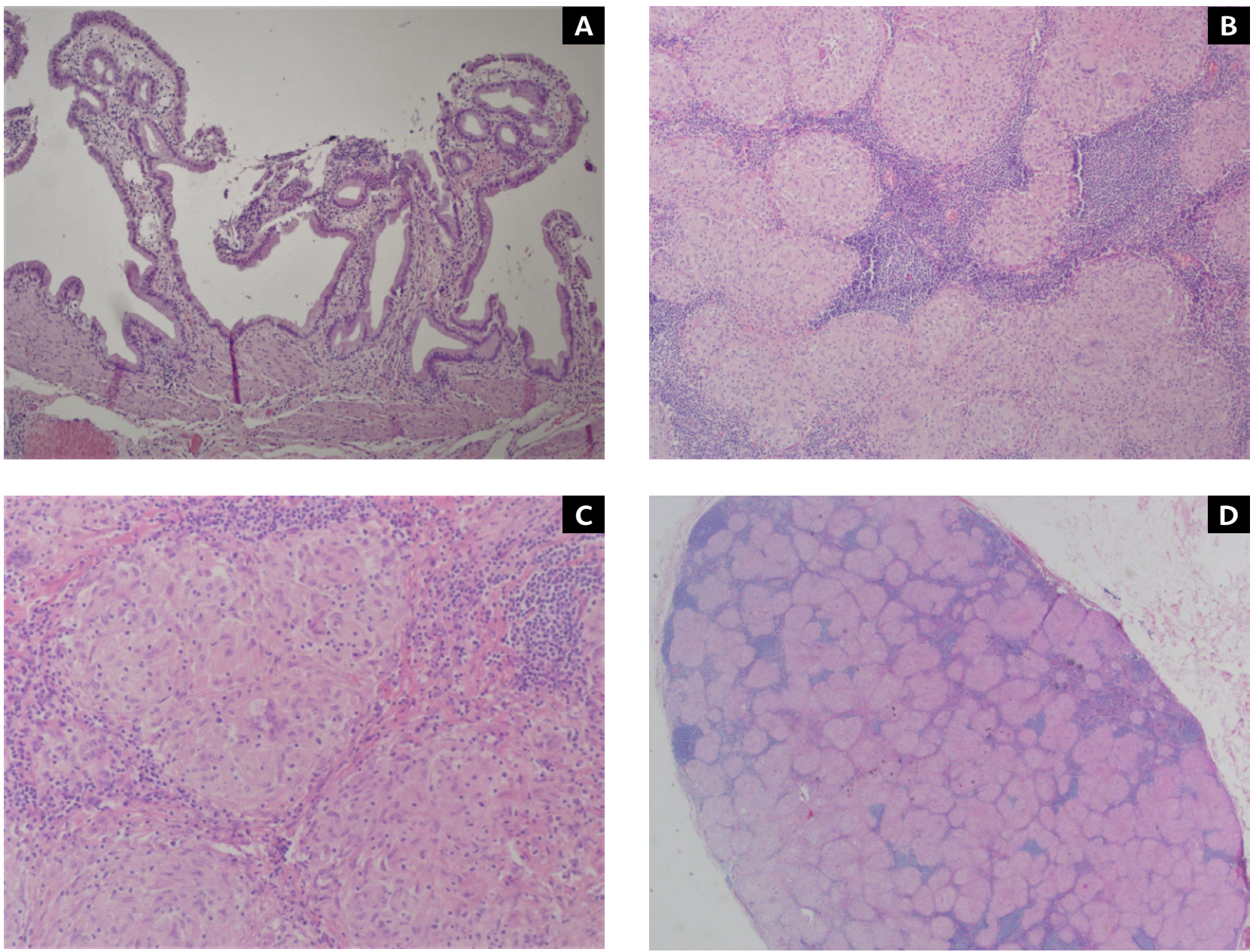

FIGURE 1. SARCOIDOSIS OF THE GALLBLADDER LYMPH NODE.

A: Low-power view of a lymph node from the gallbladder neck, showing numerous characteristic confluent granulomas (H\&E, $\mathrm{x} 20$ ). B and C: High-power view of a non-caseating granuloma composed of epithelioid histiocytes and multinucleated giant cells with an asteroid body (arrow) (H\&E, x40,x200). D: Histopathologic findings of chronic cholecystitis and cholesterolosis in the gallbladder (H\&E, x100).

surgery was planned but during the operation, open cholecystectomy was performed because of widespread intra-abdominal adhesions secondary to the previous operation. The postoperative follow-up period was uneventful and she was discharged postoperatively on the second day.

The postoperative histopathological examination of the gallbladder wall showed signs of chronic cholecystitis and cholesterolosis. The lymph node in the gallbladder neck revealed numerous granuloma structures. The granulomas were associated with each other and they consisted of small size, non-necrotized, epithelioid histiocytes and multinuclear giant cells (Figure 1).

An asteroid body (small, intracytoplasmic, eosinophilic star-shaped structure) was seen in the giant cell cytoplasm. Non-necrotizing granulomatous lymphadenitis was identified at the lymph node of the gallbladder. Acid-resistant bacilli (AFB) were negative. The findings suggested sarcoidosis. Postoperative, the patient was referred to the pulmonary disease unit.

\section{DISCUSSION}

Sarcoidosis is a multisystemic noncaseating granulomatous disease with a prevalence of 10-20 per 100,000 individuals and frequently occurs between the second and fourth decades of life1,2. The most affected system in sarcoidosis is the lung, with lymph node involvement ${ }^{1}$. Less than $4 \%$ of sarcoidosis cases have gastrointestinal and hepatic involvement ${ }^{1}$. Sarcoidosis of the gallbladder and its associated lymph node has been reported in the literature by eight case reports ${ }^{1,3}$. Among these eight cases, only two of them 
presented gallbladder-associated lymph node involvement, as in our case ${ }^{1}$.

About half of patients with gallbladder sarcoidosis are usually asymptomatic and often diagnosed accidentally by other methods, such as chest x-ray and histopathological examination, when investigating another cause'. Symptomatic patients may present different symptoms mimicking benign or malignant conditions such as biliary colic, chronic or acute cholecystitis, chronic cholestasis, biliary fibrosis/cirrhosis, portal hypertension, Budd Chiari syndrome, obstructive jaundice ${ }^{1,2}$. Inflammation involving the biliary tree and lymph nodes may also cause extrinsic compression of the cystic canal and consequently increased jaundice. In addition, sarcoidosis may often mimic cholangiocarcinoma due to the strictures in the extrahepatic ducts ${ }^{2,4}$.

The diagnosis of gallbladder sarcoidosis should be supported by laboratory findings. Diseases that may cause non-caseified granuloma should be considered and excluded in the differential diagnosis. As in our case, tuberculosis must be excluded by performing an acid-fast bacilli (AFB) test through Ziehl-Neelsen staining.

Although in our case the patient was diagnosed after cholecystectomy operation with postoperative specimen pathology, the diagnosis of sarcoidosis is established by clinical, radiologic, and histopathologic findings.

Prednisolone is the most prominent drug for the treatment of systemic sarcoidosis. However, there is limited literature based on case reports about the specific treatment of gallbladder sarcoidosis, ${ }^{1,2}$. Laparoscopic or conventional cholecystectomy is the treatment of choice for patients with gallbladder sarcoidosis.

\section{CONCLUSION}

Cholecystectomy must be performed to patients with symptomatic cholelithiasis with or without a previous diagnosis of sarcoidosis. Symptomatic cholelithiasis may be the first sign of sarcoidosis. It is important to follow up on the postoperative specimen material.

\section{Informed Consent}

Informed consent was obtained from the patient for publication of this case report

\section{Conflict of Interest}

No conflict of interest was declared by all the authors.

\section{Financial Disclosure}

The authors declare that this study has received no financial support.

\section{RESUMO}

A sarcoidose é uma doença granulomatosa multissistêmica não-caseosa que raramente afeta o sistema gastrointestinal. O diagnóstico inicial de sarcoidose com envolvimento de linfonodo da vesícula biliar ou associado à vesícula biliar é muito raro na literatura. Aqui, o nosso objetivo foi relatar um caso de sarcoidose recém-diagnosticado com envolvimento de linfonodos associados à vesícula biliar.

PALAVRAS-CHAVE: Sarcoidose. Colelitíase. Vesícula biliar.

\section{REFERENCES}

1. Ho ITL, Tan HI, Tan CS, Chiow AKH. The odd gallbladder - a rare case of gallbladder and lymph node sarcoidosis: a case report and review of the literature. J Gastrointest Cancer. 2019;50(3):699-702.

2. Gezer NS, Başara I, Altay C, Harman M, Rocher L, Karabulut N, et al. Abdominal sarcoidosis: cross-sectional imaging findings. Diagn Interv Radiol. 2015;21(2):111-7.
3. Kesici B, Toros AB, Bayraktar L, Dervisoglu A. Sarcoidosis incidentally diagnosed: a case report. Case Rep Pulmonol. 2014;2014:702868.

4. Bloom R, Sybert A, Mascatello V|. Granulomatous biliary tract obstruction due to sarcoidosis. Report of a case and review of the literature. Am Rev Respir Dis. 1978;117(4):783-7. 